\title{
Yes, Virginia, There is a Santa Claus
}

\author{
MICHAEL WREEN
}

Marquette University
The bulk of this paper is a finegrained critical analysis of a single argument. Such detailed treatment, unusual though it is in a journal article, is warranted for a number of reasons, I think. First, a clear understanding of the particular argument in question demands close attention. Different arguments can, and do, warrant different degrees, kinds, and depths of analysis, and the one under consideration here, as I hope to show, needs more than most. But the proof of that, of course, is in the reading.

Second, the 'new wave' theorists[1] -yours truly among them- rarely condescend to case studies, though their entire theoretical approach, whether formalisitc or non-formalistic, demands close attention to the details of everyday argumentation. 'New wavers,' in other words, have (in the main) not considered arguments oneby-one on their own merits, or tentatively theorized on the basis of data collected in the field but analyzed in the lab.[2] Rather, they have 'punked out,' followed their elders, and offered quick theories based on small samples of data-actual everyday argumentsthat have not been subjected to analysis. This paper, at least, offers a little lab work

Third, the argument under conside- ration is supposedly an ad baculum (primarily), and my critical analysis helps to shed some light, even if only indirectly, on the argument-type, or at least textbook treatments of it. In part for the reasons just indicated, a full critical review of ad baculum is too large a project to undertake here; [3] but some small start is made.

Fourth, the argument is interesting in its own right, and critically analyzing it fun. That may be the best reason of all for a detailed treatment, at least if we don't forget that one of the main reasons those of us who read and write for the journals do so is the stimulation and exhilaration that intellectual matters provide. We may be too old or stiff for basketball or roller skating, but give us an interesting intellectual problem to mull over for an hour or two, and it doesn't make any difference. And there's nothing wrong with that.

That said, let me indicate the organization of the paper. In section 11 , the argument that will be under the microscope is first presented, then evaluated in accordance with what might be called standard assessment criteria. A reconstruction is begun in section III, disctinctions are also introduced there, and one charge brought against the argument-the main one, in fact-is found to be without basis. The reconstruction is continued in 
section IV, where the argument is brought before the dock on another charge. The verdict is again not guilty, however; but, as the analysis provided there shows, the argument is guilty of a third charge, one not considered, or even capable of being considered, if analysis is kept on a superficial level. As I try to show in section $V$, though, that doesn't mean that a person who offers or accepts such an argument is, to that extent, irrational. More than mere argument strength has to be taken into consideration in judging such matters. Critical analysis of the argument having been completed in section $\mathrm{V}, \mathrm{I}$ consider, in section $\mathrm{VI}$, an important objection to the analysis. Finally, in section VII, I extend my finding somewhat and speculate on the theoretical framework that generates summary dismissals of arguments with the charge of 'fallacy.' My tone, as might be guessed, is polemical throughout.

\section{II}

Consider the following argument: Of course there is a Santa Claus. But he just doesn't bring any presents to children who don't believe in him.

This argument appears in Irving Copi's well-known Introduction to Logic, [4] and it or a near relative is frequently cited in logic texts and journal articles as an example of a fallacious argument.[5] What is the fallacy committed here? In all probability, the primary one is appeal to force, or arqumentum ad baculum, since being argued is that the claim

You ought to believe that there is a Santa Claus, should be accepted for the reason that

You aren't going to receive any Christmas presents if you don't believe in Santa Claus.

Such an argument undoubtedly has no logical force, i.e., purely rational convincingness. (But more on rational convincingness below.)

But more than that, what is also

being argued is that

There is a Santa Claus,

The reason for this being that

Santa Claus doesn't bring any presents to children who don't believe in him.

After all, what the person presenting this argument is trying to convince his/her interlocutor of is the existence of Santa; that is, he/she is trying to show that Santa really does exist.

Thus rendered, the argument is blatantly circular or question-begging: implicit in the premise is the claim that there is a Santa Claus - just what is to be proved.

\section{III}

So, at any rate, would be the critical evaluation of the argument from the point of view of standard fallacy theory. Thus convicted, the Santa Claus Argument would probably be summarily dismissed. (Actually, Copi himself convicts it only of ad baculum. However, as the original argument is undoubtedly supposed to provide, inter alia, evidence for Santa Claus's existence, a relatively complete reconstruction would probably tease out a charge of petitio principii as well. Thus the argument in its dual reconstructed form will be considered in this paper.) But although I don't in fact think the argument a strong one, I doubt that the standard evaluation of it is adequate, and I don't think it can be quite so quickly dismissed.

First of all, what, in all likelihood, is the context in which the Santa Claus Argument is offered? None is provided by the text, so I'll have to impute one. Probably this, I would guess: a childcall her Virginia-who has formerly believed in Santa Claus has been told by an older sibling or friend that there is no Santa Claus. Virginia has returned to her parents, the source of her original belief in Santa, a belief which 
is now shaken - she has returned to ask them whether there really is a Santa Claus. The Santa Claus Argument is the response of one of her parentsher mother, let's say-to Virginia's question, "Is there really a Santa Claus?". So much, at least, seems to be the likely context, or at least a likely context, in which the argument would be advanced.

That being at least a plausible context, let's see whether the questionbegging and appeal to force charges really stick. First, the appeal to force charge.

The argument here, remember, is:

You aren't going to receive any presents if you don't believe in Santa Claus.

Therefore, you ought to believe in Santa Claus.

This argument is undoubtedly invalid if the 'ought' in the conclusion is the 'ought' of rationality or rational convincingness, i.e., the 'ought' that has to do with providing good reasons for the truth of the proposition that 'ought to be believed.' " 1 'll torture you if you don't beleive that the Sun revolves around the Earth" provides absolutely no grounds for the truth of the claim that the Sun revolves around the Earth. But the 'ought' of rationality isn't the only 'ought,' and frequently, especially in a dialectical context, such as we have here, it isn't the 'ought' that's meant. Let's take context into consideration, then, and interpret the argument in as charitable a way as possible.

One other 'ought' frequently employed in dialectical contexts is the 'ought' of self-interest. "You ought to invest your money at $15 \%$, not $5 \%$, ,' for example, should be interpreted as "you ought, as a matter of prudence (i.e., from the point of view of selfinterest), to invest your money at $15 \%$, not $5 \%$." The 'ought' of selfinterest has to do with doing something or being in a certain state, namely doing something or being in a certain state in order to maximize self-interest. Reinterpreted charitably, our argument, alleged to commit the fallacy of appeal to force, contains an 'ought' of self-interest, and reads:

You aren't going to receive any Christmas presents if you don't believe in Santa Claus.

Therefore, you ought, from the point of view of self-interest, to believe in Santa.

Is this argument fallacious? Would the truth of the premise strongly support the truth of the conclusion? Sure it would. If the premise is trueand it may well be, since mothers are very good at determining what the beliefs of their children are, and Virginia's mother may well be nasty enough not to give her any Christmas presents if she doesn't believe in Santa (I say this because she offers the Santa Claus Argument in the first place) - the conclusion would be very well supported. It does supply very good evidence for the conclusion, in other words. Virginia's mother isn't stupid in offering the argument, and Virginia isn't stupid in taking it to be valid, in the broad sense of the term.

\section{IV}

What of the supposed questionbegging argument? That argument is:

Santa Claus doesn't bring presents to children who don't believe in him.

Therefore, Santa Claus exists.

In order to evaluate this argument properly, the context in which it is advanced once again has to be taken into consideration. In this regard the most important point to note is that the argument is offered in response to Virginia's airing her recently acquired doubt about the existence of Santa. Her question, Does Santa Claus really exist?, is directed to the very person responsible for her belief in Santa in the first place, and it has 
been prompted by having been told, by other children, we'll say, that there is no Santa. The other children, we may safely assume, have always or usually been reliable sources of information, at least so far as Virginia has been able to determine. Her mother's task, then, given her overarching objective to 'keep Virginia an innocent, sweet child'-at least that's a plausible objective to impute to her-is thus set: she must overcome the contrary evidence now at Virginia's disposal, and so keep little $V$.'s belief intact. She must explain away or discredit the contrary evidence, that is, show that it is ill founded. This she does by citing a (supposed) fact about Santa Claus that the child wasn't previously aware of, namely that Santa behaves in a certain way-he doens't give presents-under certain conditionswhen the prospective present-getter doesn't believe in him. This effectively impugns the contrary evidence (1) by explaining why the other children would think there is no Santa Claus they haven't believed, perhaps from the start, that there is a Santa, and so have received no presents (at least Virginia's mother suggests as much) - and (2) by explaining why the other children would erroneously believe that there is no Santa-their not receiving presents has reinforced their belief that there is no Santa (the other children, in other words, are caught in a vicious, self-reinforcing cycle). Virginia's mother suggests that, on the contrary, their receiving no presents is not at all the result of there not being a Santa, but of their, the other children's, not believing that there is such a being. Thus the mother explains away, discredits the contrary evidence.

Let me try to make this clearer. Sometimes when we believe something, our belief causes something to occur (think of belief here as a psychological state that has causal effects, not as a proposition). If I believe that your shirt is on fire, that may cause me to say as much; and that, in turn, may cause you to believe that your shirt is on fire, and so cause you to douse it.

What Virginia's mother is saying is basically this: "If you believe that Santa Claus doesn't exist, that will cause Santa to know that you believe that he doesn't exist. (Santa's ways, including his ways of knowing, are not our way-which isn't surprising, given that he makes millions of toys every year, gives them away for free, manages to visit millions of homes in a single night, etc.) And if he knows that you believe that he doesn't exist, he won't bring you any presents. (Santa Claus is a touchy guy; he's offended by people who don't believe in him-which is only to be expected, given that he puts out such a gigantic effort for others and is so very generous.) Your friends started out on the wrong foot, or got screwed up somewhere along the line, by not believing in Santa. They then received, or maybe received from the start, no presents, and wronglybecause they didn't understand the true nature of Santa-took that fact as evidence that Santa doesn't exist." This explains both why the other children would believe that Santa doesn't exist, and why the belief they have is ill-founded, in fact false. Thus the contrary evidence is discredited, and Virginia's belief in Santa protected. The mother's argument in context, then, is not a 'from scratch' attempt to show that Santa exists-which is how it would have to be taken to make the question-begging charge stickbut an attempt to beat down an objection, explain away contrary evidence.

It is not a good explanatory, protective argument, however-but its fault does not lie with its being questionbegging. Rather, it is a bad explanatory, protective argument for two very different reasons. (A) There is no prior, independent, epistemically -fully-reputable evidence-that is, independant evidence available to epistemically sophisticated subjects in a very good position to know-at anyone's disposal for the existence of Santa. This means that the explanatory, protective argument is predicated on a 
belief for which there is, in effect, no evidence at all. But this we know on grounds independent of those specified either in the Santa Claus Argument itself or in the context of dispute-the dialectical context-described above. (B) The explanation Virginia's mother gives, invoking as it does very peculiar causal connections and a very peculiar individual, is extremely implausible. But this we also know on grounds independent of those specified in the Santa Claus argument or in the context of dispute-the dialectical contextdescribed above. In short, we know that there is no reason to think that Santa Claus exists, and that the world just doesn't operate the way that Virginia's mother suggests it does. We know that the explanatory, protective argument is no good, then, because we bring all relevant information, including information not specified in the argument or context as such, to bear when assessing it. As always, we should use all relevant information in evaluating arguments.

\section{V}

Two additional points. Given that We know that it is a bad explanatory, protective argument, should we say that Virginia is irrational or logically at fault for holding the argument to be a good one (assuming that she does think it a good one)? No, not at all. Young children have to accept many things their parents tell them just because they don't have many other sources of information, and certainly not many other reliable sources of extensive information about (from their point of view) esoteric matters. Besides, parents usually tell the truth. Thus, although we know that there is no (epistemically fully-reputable) evidence for Santa's existence, and that the world doesn't contain such odd causal connections and individuals as Virginia's mother alleges, Virginia is in no position to know as much. So it would not be irrational for her to believe that Santa exists or that the explanatory, protective argument is a good argument: reasons (A) and
(B) for thinking it bad are not reasons that Virginia could be reasonably expected to know. In fact, it would be reasonable for her to believe that Santa exists, and that the explanatory, protective argument in a good one. Her parents are more reliable sources of informations than anyone else, are older and know more than children, and have taken good care of her in the past (in this last respect, remember the accompanying ad baculum, too).

Second point. Virginia's mother knew all of the above before she answered Virginia's challenge with the Santa Claus Argument, and she knew that saying what she did would probably be causally efficacious, would probably protect, and maybe even reinforce, Virginia's belief in Santa. Given her overarching aim, it is certainly not irrational of her to offer the argument.

Virginia is not irrational in accepting the Santa Claus Argument, then, and her mother not irrational in advancing it. I don't want to be too abrasive about the matter, but if anyone is irrational it is Copi.[6] He is a philosopher, and in fact the author of a logic text that has seen seven editions; and he offers the Santa Claus Argument in an exercise set in said text. But apparently he would have us believe that the argument is of no worth because it is fallacious. Indeed, as we have seen, it is fallaciousbut not because it is an appeal to force, as Copi would undoubtedly have it, or a petitio principii. It is fallacious because there is no good reason for thinking that there is such a being as Santa Claus. And Copi would also have us believe, it would seem-it is a traditional logic text, after all-that anyone who would offer or believe such a fallacious argument is, to that extent at least, irrational. The argument may not be a good one, and Santa may not exist, but the argument's weakness is not its supposed appeal to force or question-beggingness, and Virginia and her mother are not irrational in, respectively, advancing and accepting it. 
V1

At least one major objection might be raised to my treatment of the Santa Claus Argument, however. This is quite simply that Copi, the villain of this piece, just would not say what I have him say. In particular, he would not-in fact, he does not-say that the argument is a petitio principii. Thus much of this paper is just an unfair attack on an innocent victim.

This is an important objection. Let me begin my reply to it by noting that Copi does say that the argument is an ad baculum. [7] Hence, at least the earlier sections of this paper are directed against a position that Copi himself explicitly holds. He does not say it is a petitio, however. But, for three reasons, I don't think that convicts my treatment in section IV and V of this paper.

First, if the ad baculum charge is defused, Copi is left with the position that the argument is logically flawless. It obviously isn't, though. The next place to search for something wrong, even if Copi himself doesn't search there (namely, because he thinks the argument already guilty of ad baculum), is in the area of petitio.

Even without an explicit reconstruction, it's fairly obvious that the existence of Santa is assumed by the statement purporting to support the claim that 'of course there's a Santa Claus.'

Second, Copi himself never reconstructs this or any other argument. His method of fallacy detection consists in putting forth a short passage and then judging, on the basis of intellectual intuition, apparently, which of the fallacies on his list the passage is guilty of (if indeed it's guilty of any). Absolutely nothing more is provided by him-or a goodly number of other authors, either. If a fallacy is committed in a passage, however, there must be an argument in it, and the inference from the premises to the conclusion must be a bad one. For fallacies are illegitimate inferences, and so the only way to tell whether a fallacy has been commited is by knowing what inference, from what premises to what conclusion, has been made. The only way to know that is by knowing what the premises and conclusion are. In most cases, that requires an explicit reconstruction. When the Santa Claus Argument is explicitly reconstructed, though, then, as mentioned in section II, the main conclusion that's apparently being argued for is that Santa Claus exists - that's what Virginia's mother is trying to convince her of, after all. Such a reconstruction, however, immediately invites a charge of circularity. Thus, even if Copi doesn't claim that the argument is guilty of petitio, the fact that he convicts it of any charge at all implicitly invokes the notion of reconstruction; and the reconstruction that is most imperative, namely one that identifies the main conclusion as

\section{Santa exists,}

would have the argument, at least on a superficial analysis of it, guilty of petitio.

Third and last, a reading of it as prima facie circular is at least plausible irrespective of what Copi himself says. If the argument

Of course there's an either; it's just too subtle to be detected by our crude instruments,

were offered, I would see it as, on the surface, question-begging (though, in context, as an explanatory, protective argument it may or may not be fairly strong, depending on other factors). The Santa Claus Argument is no different in this regard. Rendering it as a petitio and critically exploring it as such, then, is justifiable regardless of what Copi would, or does, say.

\section{VII}

Besides defending my treatment of the Santa Claus Argument, I'd like to back up my claim that Copi's superficial handling of the Santa Claus Argument is typical-typical both of him and of other authors of logic texts. 
In addition to the Santa Claus Argument, Copi himself presents eight other arguments which he convicts of ad baculum. Two can be found in his explanatory introduction to the argument-type,[8] the other six in his exercise sets. [9] I'll discuss five of the six in his exercise sets elsewhere, [10] so I won't repeat what I say there here. My findings, though, I think should be noted: given plausible background assumptions, five of the six are quite strong, and the one that isn't, isn't for reasons independent of the fact that the argument is an ad baculum.

But consider also one of the examples Copi uses when he introduces the (so-called) fallacy in the first place.

The lobbyist uses the ad baculum when he reminds a representateve that he (the lobbyist) can influence so many thousands of voters in the representative's constituency, or so many potential contributors to campaign funds. Logically these considerations have nothing to do with the merit of the legislation the lobbyist is attempting to influence. But they may be, unfortunately, very persuasive.

But the lobbyist knows as well as anyone else that what he's said doesn't show that the bill is a good one. He's not arguing that the bill is good because he can influence voters. No one smart enough to become a lobbyist is dumb enough to think that. What's he's arguing is that if the politician doesn't support the bill, he won't use his influence to help him, the politician, get re-elected. His conclusion is not that the bill is a good one, but that the politician ought, from the point of view of self-interest, to support it. That argument may well be quite strong, regardless of the fact that it's an appeal to force. As I said above, Copi's procedure with informal fallacies is to consider a short passage, then, on the basis of a intuitive matching of the passage with a fallacy, or with fallacies, on his list of same, to convict it (or, if there is no match, to declare it innocent). Such a brisk and unreflective treatment invites not just a more in-depth treatment of particular arguments, such as I have offered above, but a condemnation of the procedure itself.

Nor is Copi alone in handling informal fallacies this particular way. Many authors of logic texts tell, if not exactly the same story, at least a very similar one.[11]

Why, though, does Copi tell the story he does? And why do other theorists tell the (similar) ones they do? Concentrating just on Copi now, why does he use the erroneous framework for the analysis and evaluation of arguments that he does? I can only speculate, but the answer, I suspect, has a lot to do with tradition. Informal fallacies have been bequeathed us by a long line of venerable philosophers, starting with Aristotle. Many even come with impressive latin labels and an illustrative example or two, an example or two about which we feel that something is wrong (more on this below). But they also come with little more than a brief description to indicate their nature, and no theoretical justification for why arguments of that particular type are fallacious. What Copi has done is what many philosophers before him have, namely pass on the tradition unanalyzed, in much the same form that he received it. There would be nothing wrong with this if informal fallacies, and ad baculum in particular, had once been subjected to critical scrutiny and passed the test. Then the inheritance would have proven its worth. But, prior to the last fifteen years or so, the gift horse has never been looked in the mouth. Given what we've been bequeathed, then, a superficial treatment of everyday arguments, based on matching them with a preordained list of (so-called) fallacies, is what is to be expected. This is especially true when, as in the case of the lobbyist, we know that something is wrong with the argument that's been proffered. What is wrong in that particular case, though, is ethical, not logical: the lobbyist is guilty of a moral fault, in trying to straightarm the politician. And similarly in the 
case of the Santa Claus Argument: we all think that something is wrongthough our judgment in that case is probably more fueled by our assurance that there is no Santa Claus than it is, in a secondary way, by our moral disapproval of the mother's behavior. Not stupidity, and not lack of logical acumen, explains the superficial and devective treatment of informal fallacies frequently found in logic texts, but an uncritical acceptance of a tradition coupled with a feeling that something is wrong in the illustrative examples that come complete with latin handles. But, as Socrates himself would say, only an examined fallacy is worth having.[12]

\section{Notes}

[1] I borrow the term from Ralph $\mathrm{H}$. Johnson and J. Anthony Blair, "the Recent Development of Informal Logic," in Ralph $\mathrm{H}$. Johnson and J. Anthony Blair, eds., Informal Logic: The First International Symposium (Point Reyes, CA: Edgepress, 1980,) p. 13.

[2] The parenthetical "in the main" is important here, for some 'new wavers,' I'm happy to say, do pay close attention to everyday-life arguments, and do analyse and evaluate them without a checklist of standard fallacies, or some other form of heavy theoretical baggage, in hand. I have in mind Howard Kahane, Logic and Contemporary Rhetoric 4th edition (Belmont, CA: Wadsworth Publishing Company, 1984); J. Anthony Blair and Ralph Johnson, Logical Self-Defense (New York: McGraw-Hill, 1977); and Trudy Govier, A Practical Study of Argument (Belmont, CA: Wadsworth Publishing Company, 1985). Some of the better journal literature, containing theoretical treat- ments of the fallacies, but sensitive to the realities of everydaylife argumentation, include Trudy Govier, "Logical Analogies," Informal Logic 7 (1985); "What's Wrong with Slippery Slope Arguments?" Canadian Journal of Philosophy 12 (1982); and Leo Groarke, "When Two Wrongs Make a Right" Informal Logic Newsletter 5 (1982).

[3] In "May the Force Be with You," Argumentation (forthcoming) and "A Bolt of Fear," in preparation, however, I do offer an assessment of the argument-type.

[4] Irving Copi, Introduction to Logic, 7th edition (Macmillan, New York: 1986), p. 110.

[5] See, e.g. Dwight Van de Vate, Jr., "The Appeal to Force", Philosophy and Rhetoric 8 (1975), 43.

[6] And, of course, other authors of texts and articles who offer the argument for summary classification ('ad baculum' and/or 'petitio principii'), appraisal ('therefore fallacious'), and dismissal as well, when they should know better. I'm afraid that just such a treatment of informal arguments is encouraged by many of the introductory logic texts currently on the market. See section VII and fn. 11 in this regard.

[7] See his Solutions to Exercises: Introduction to Logic, 7th edition (New York: Macmillan, 1986), p. 49 .

[8] Copi, Introduction to Logic, op. cit., pp. 91-92.

[9] Ibid., pp. 106, 107, 112, 127, 128.

[10] In "May the Force Be with You," op. cit.

[11] In my estimation, superficial or defective treatments of ad baculum occur with a fair amount of frequency. The treatment in following texts, for example, seems to me in need of correction: Robert Baum, 
Logic 2nd edition (New York: Holt, Rinehart, and Winston, 1981), pp. 133-134; Robert Paul Churchill, Becoming Logical (New York: St. Martin's Press, 1986), p. 436; William Halverson, A Concise Logic (New York: Random House, 1984), pp. 5556; Nicholas Capaldi, The Art of Deception (Buffalo, NY.: Prometheus Books, 1974), p. 140; Patrick Hurley, A Concise Introduction to Logic, 2nd edition (Belmont, CA: Wasdsworth Publishing, 1985), pp. 102-103; S. Morris
Engel, With Good Reason (New York, St. Martin's Press, 1976), pp. 130-133; Jerry Cederblom and David W. Paulsen, Critical Reasoning (Belmont, CA: Wadsworth Publishing, 1982), pp. 100-101.

[12] My thanks to J.Anthony Blair and an anonymous referee for a number of useful comments on an earlier draft of this paper.

Professor Michael J. Wreen, Department of Philosophy, Marquette University, Milwaukee, Wisconsin $53233 \square$ 